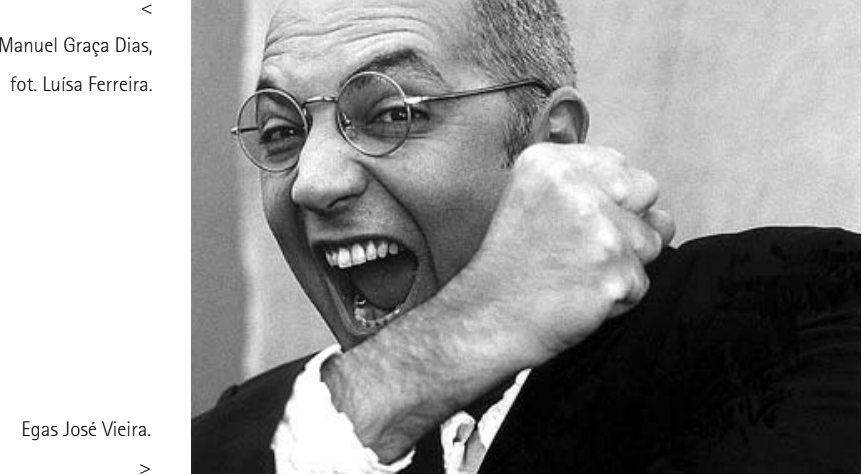

\section{Manuel Graça Dias}

Nasceu em Lisboa, em 1953. Formou-se em Arquitectura pela Escola Superior de Belas Artes de Lisboa (1977). Fez a sua primeira cenografia para o filme O lugar do morto, de António-Pedro de Vasconcelos (1982), e estreou-se no teatro, em colaboração com Egas José Vieira, na encenação de Mário Feliciano da peça $D$. João e a máscara, de António Patrício (Teatro da Politécnica, 1989). Actualmente, lecciona na Faculdade de Arquitectura da Universidade do Porto e no Departamento de Arquitectura da Universidade Autónoma de Lisboa, colaborando ainda com a Facoltá di Architettura do Politécnico de Milão. Foi já distinguido com diversos prémios na arquitectura, bem como no trabalho de cenografia.

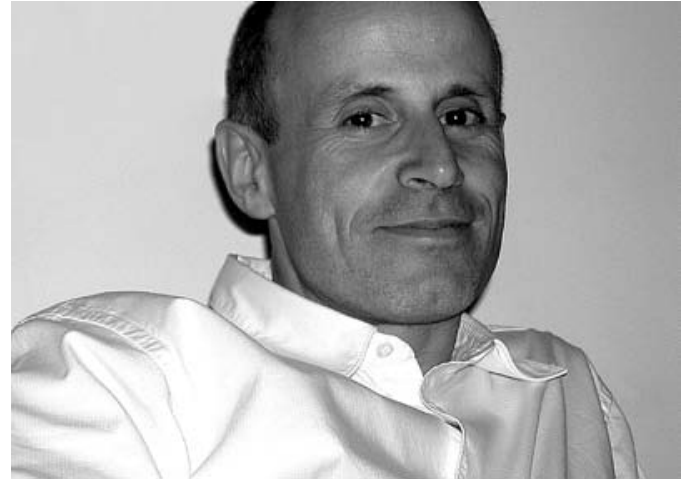

Egas José Vieira

Nasceu em Lisboa, em 1962. Licenciou-se em Arquitectura pela Universidade Técnica de Lisboa, em 1985. Realizou o primeiro trabalho cenográfico no teatro para o Grupo de Campolide / Companhia de Teatro de Almada, com Georges Dandin, de Molière (1986). Nesse mesmo ano, iniciara a colaboração com a companhia dirigida por Joaquim Benite, desenhando os figurinos para A menina Júlia (encenação de Rogério de Carvalho e cenário de José Manuel Castanheira). Em ambas as produções, foi ainda responsável pelo material gráfico. É, actualmente, professor no Departamento de Arquitectura da Universidade Autónoma de Lisboa e, em conjunto com Manuel Graça Dias, desenvolve actividade no atelier Contemporânea, em Lisboa.

\title{
Um trabalho em equipa, para ir sempre mais longe
}

\section{Selda Soares}

Manuel Graça Dias e Egas José Vieira assumem o trabalho arquitectónico e cenográfico como uma responsabilidade a dois. Encontraram-se no projecto de cenografia para a peça $D$. João e a máscara, trabalho distinguido com a atribuição do Prémio Garrett, da Secretaria de Estado da Cultura. Foi o início de uma parceria que se vem prolongando no tempo, essencialmente ligada às duas companhias com as quais trabalharam e - num dos casos - ainda trabalham. Para o Teatro da Politécnica, conceberam ainda a cenografia para Casa de boneca, de Ibsen, em 1990, e, dois anos mais tarde, para Dinis e Isabel, de António Patrício, espectáculo também encenado por Mário Feliciano e que se estreou no Teatro da Trindade, no âmbito de um Ciclo de Teatro de Câmara. Apesar da designação deste ciclo, o trabalho envolveu meios
O trabalho de equipa é um processo que está lançado. Tanto faz se fui eu que lancei a ideia ou se foi ele. Foi um de nós. Em vários momentos, há um que se adianta e o outro introduz correcções. Não é aquela atitude de ver quem dá mais contributos. É ir mais longe. 0 que é muito interessante no trabalho de equipa é que se vai sempre mais longe do que qualquer um de nós iria sozinho.

complexos, contando com um elenco de vinte e cinco actores, para quem Ana Salazar foi chamada a desenhar os figurinos. Para a Companhia de Teatro de Almada, conceberam ainda o espaço cénico para Mãe Coragem e os seus filhos, de Brecht (2000), 0 mercador de Veneza, de Shakespeare (2002) e Paolo Paoli, de Adamov (2003).

No contexto do Festival Internacional de Lisboa, na sua quarta edição, trabalharam com o encenador Ricardo Pais, no seu espectáculo Fados que, em 1994, subiu ao palco do Grande Auditório do Centro Cultural de Belém. Contam-se ainda no historial de ambos colaborações com o Teatro Nacional de S. Carlos, para as encenações de Paulo Ferreira de Castro das óperas Fidélio, de Beethoven (1993), e Les Troyens, de Berlioz (1997 e 1998, respectivamente, a primeira e a segunda partes). 

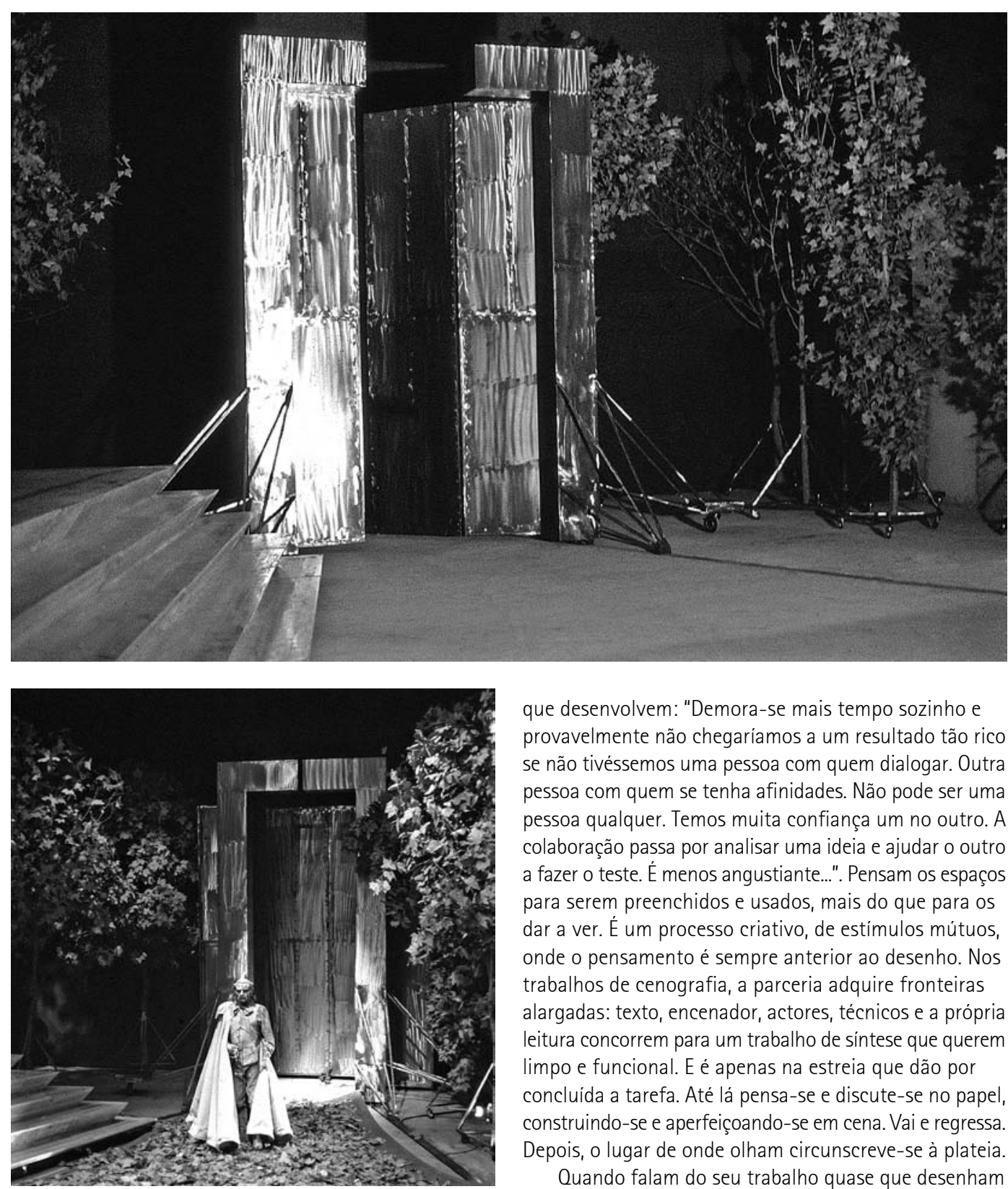

Embora Egas José Vieira se tenha iniciado no teatro com o desenho de figurinos, reconhece que essa experiência "não dava aquele prazer, nem o à vontade necessário para associações mais criativas e mais elaboradas", como posteriormente veio a encontrar na cenografia, "uma espécie de prolongamento, de extensão, da arquitectura"'. Outro campo ligado à actividade teatral - o aspecto gráfico dos programas - tem merecido a sua atenção e reconhece que é ainda a questão da imagem que o seduz. Fê-lo a propósito de A menina Júlia e Georges Dandin, como mais tarde fará com Felicidade e erva-doce (1989) e Vida do grande D. Quixote de La Mancha e do gordo Sancho Pança (1992). São, ainda, seus alguns textos que promovem os espectáculos postos em cena por esta companhia. Trata-se de um trabalho de sintese por vezes a partir de uma imagem, também criada por ele, em diálogo com materiais de indole diversa.

Manuel Graça Dias e Egas José Vieira partilham o espaço de trabalho, os projectos e a vontade. Une-os uma afinidade imprescindivel para o trabalho de equipa que desenvolvem: "Demora-se mais tempo sozinho e provavelmente não chegaríamos a um resultado tão rico se não tivéssemos uma pessoa com quem dialogar. Outra pessoa com quem se tenha afinidades. Não pode ser uma pessoa qualquer. Temos muita confiança um no outro. A colaboração passa por analisar uma ideia e ajudar o outro a fazer o teste. É menos angustiante...". Pensam os espaços para serem preenchidos e usados, mais do que para os dar a ver. É um processo criativo, de estímulos mútuos, onde o pensamento é sempre anterior ao desenho. Nos trabalhos de cenografia, a parceria adquire fronteiras alargadas: texto, encenador, actores, técnicos e a própria leitura concorrem para um trabalho de sintese que querem limpo e funcional. E é apenas na estreia que dão por concluída a tarefa. Até lá pensa-se e discute-se no papel, construindo-se e aperfeiçoando-se em cena. Vai e regressa. Depois, o lugar de onde olham circunscreve-se à plateia.

Quando falam do seu trabalho quase que desenham palavras com as mãos abertas. Falam de arquitectura e de teatro como desafios. De real e de ilusão, de verdade e de simulação, de duração e de efemeridade: "A cenografia tem um prazer mais imediato. A arquitectura tem essa durabilidade, ultrapassa-nos no tempo. Nós vamos morrer e a arquitectura vai ficar". Trazem para o teatro o olhar sobre o preenchimento e o uso do espaço, que a formação académica Ihes conferiu. Falam de objectos, de maquinismos, de estruturas, mais do que telões ou variações cromáticas. da cena, por "uma certa sobriedade" do olhar e do fazer.

Em D. João e a máscara, encenado num pavilhão da Faculdade de Ciências, fascinou-os a possibilidade de preparar um espaço para receber teatro. Puderam trabalhar fora de um dispositivo cénico tradicional e projectar esse espaço para o diálogo com a cena. Investiram na novidade das estruturas que deslizavam pela sala em carris e desenvolveram as experiências com o ferro oxidado, elementos que mais tarde aproveitaram para um trabalho que misturou arquitectura e cenografia, apresentado num espaço de cariz comercial. Distinguem-se pelas escolhas simples e funcionais nos sinais
D. João e a máscara, de António Patrício, enc. Mário Feliciano, Teatro da Politécnica, 1989, fot. Manuel Graça Dias e Egas José Vieira.

D. João e a máscara, de António Patricio, enc. Mário Feliciano, Teatro da Politécnica, 1989, fot. Manuel Graça Dias e Egas José Vieira.

As declarações aqui citadas resultam de uma entrevista inédita feita com vista à escrita deste artigo. 


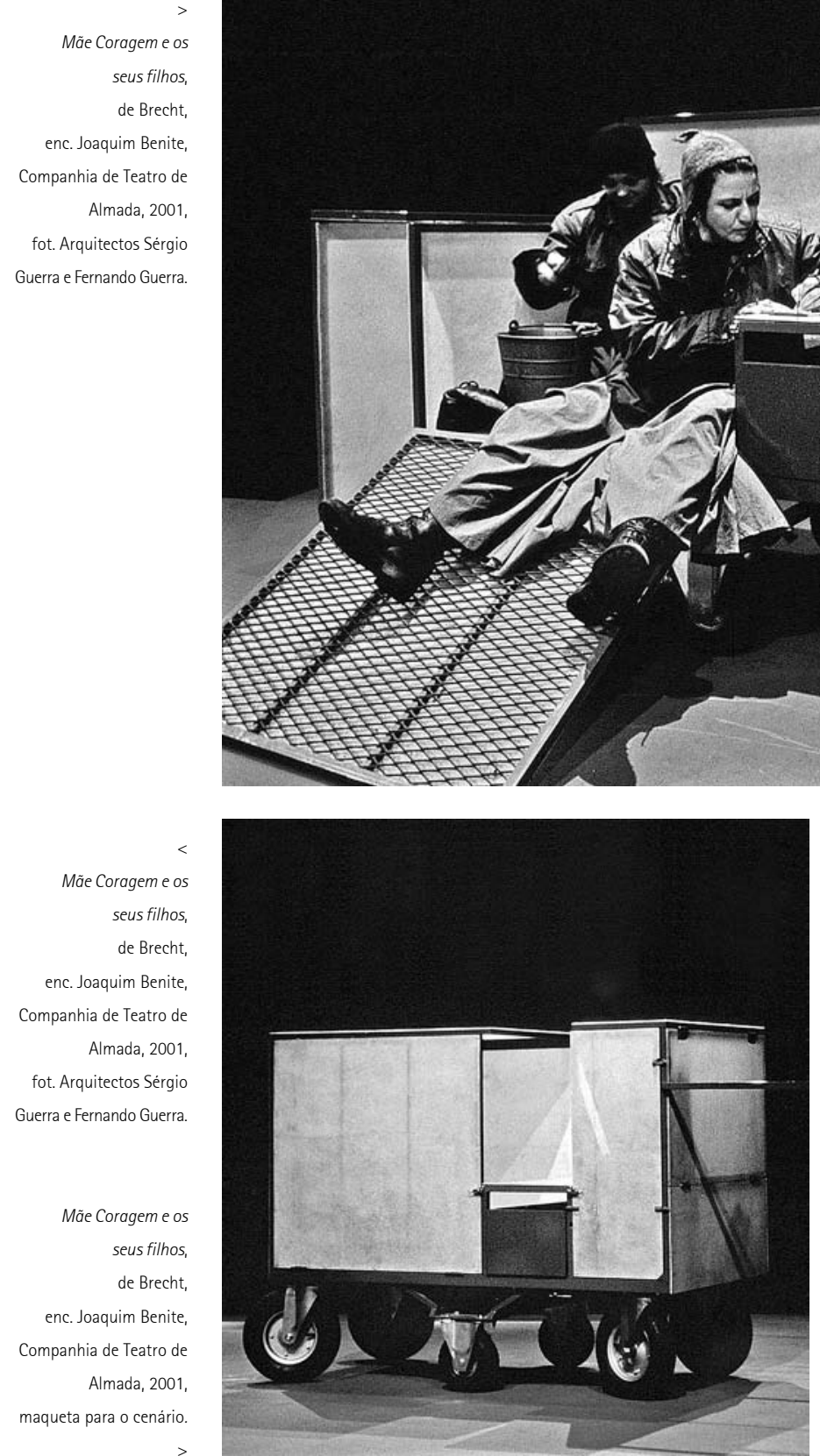

Com exigências distintas, deitaram mãos à cenografia da ópera Fidélio, tarefa que exigiu uma concepção do espaço cénico diferente da que estavam habituados no teatro. A quantidade de pessoas em cena implicou o acolhimento, em lugares distintos, do coro e das personagens. Construíram, então, plataformas rolantes numa cena que oferecia uma considerável inclinação, 0 que constituiu um desafio.

De entre as estruturas de múltiplas funções que conceberam, destacam o carro da Mãe Coragem. Nesse trabalho, a cena foi aberta até aos camarins e, para as paredes, escolheram um tom vermelho forte. 0 carro, construído em metal, circulava por todo o espaço e obedecia a uma economia na construção de sentidos. Os actores relacionavam-se activamente com esse dispositivo abrindo e fechando pequenas plataformas, subindo e descendo portas que eram mesas e escadas. E, assim, se contou a história em torno de um objecto central polivalente.

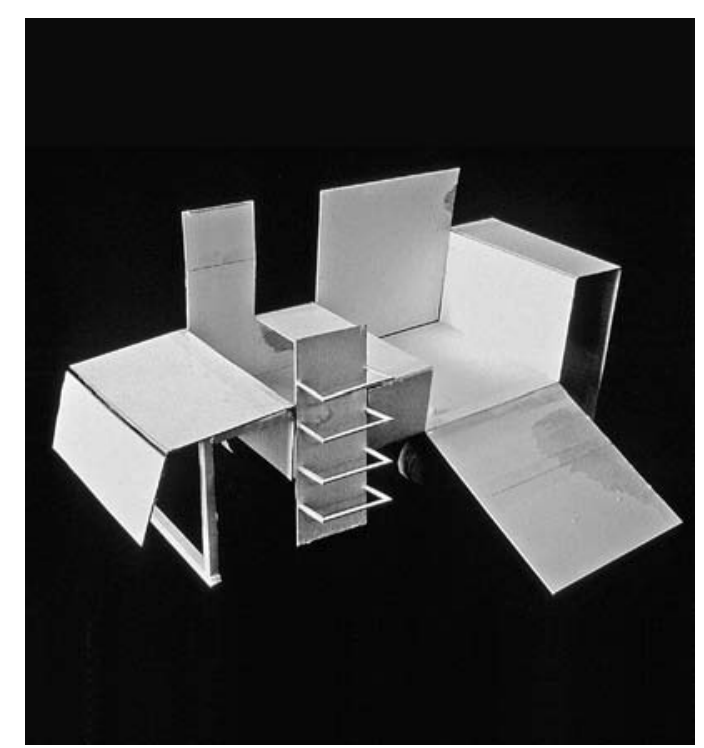

Do mesmo modo, no espectáculo 0 mercador de Veneza (2002), os blocos espalhados pelo palco propunham múltiplos usos e diversas leituras: eram chão, cais, casas, rampas. Mergulhados no tom verde da cena, que os cenógrafos quiseram que se pudesse ler como água, permitiram ancorar diversos momentos e designar diferentes espaços da intriga.

Mais recentemente, um novo projecto parece reunir toda a experiência adquirida na arquitectura e no teatro, propondo-se como um diálogo entre essas duas artes de conceber espaços e definir relações e sentidos: o projecto do Teatro Azul, em Almada. Para esse edifício, prepararam a cenografia de $D$. João, de Molière, com encenação de Joaquim Benite, que o inaugurará, em breve. Regressam, assim, à construção que ambos projectaram para a cidade - o seu novo Teatro Municipal - e fazem-no como consequência de um percurso que, na arquitectura e na cenografia, vão consolidando: em equipa, sempre. $E_{\text {, }}$ continuamente, em diálogo com os fazedores de teatro. 